\title{
Integrated modelling approaches to analysis of climate change impacts on forests and forest management
}

\author{
Asbjørn Aaheim • Rajiv Kumar Chaturvedi • \\ Anitha D. Sagadevan
}

Received: 4 March 2010 /Accepted: 11 August 2010 /

Published online: 1 September 2010

(C) The Author(s) 2010. This article is published with open access at Springerlink.com

\begin{abstract}
This paper reviews integrated economic and ecological models that address impacts and adaptation to climate change in the forest sector. Early economic model studies considered forests as one out of many possible impacts of climate change, while ecological model studies tended to limit the economic impacts to fixed priceassumptions. More recent studies include broader representations of both systems, but there are still few studies which can be regarded fully integrated. Full integration of ecological and economic models is needed to address forest management under climate change appropriately. The conclusion so far is that there are vast uncertainties about how climate change affects forests. This is partly due to the limited knowledge about the global implications of the social and economical adaptation to the effects of climate change on forests.
\end{abstract}

Keywords Forests $\cdot$ Climate change $\cdot$ Impacts $\cdot$ Adaptation $\cdot$ Integrated modelling

\section{Introduction}

Forests play a key role in managing climate change. The growth of biomass has a direct impact on the release of carbon to the atmosphere, biofuels is a substitute for fossil fuels, and afforestation prevents irrigation, which may be a way to adapt to climate change. A careful control of forested areas, harvest and composition of species may lead to synergies between mitigation and adaptation. However, forests are themselves affected by climate change, and forest management serves other objectives

\footnotetext{
A. Aaheim $(\triangle)$

CICERO, P.O. Box 1129, Blindern, Oslo 0318, Norway

e-mail: asbjorn.aaheim@cicero.uio.no

R. K. Chaturvedi · A. D. Sagadevan

Centre for Sustainable Technology, Indian Institute of Science, Bangalore 560 012, India
} 
than climate policies, such as supplying timber, sustaining biodiversity and tourism. This turns forest management into a challenging task, with integration of many different objectives.

Studies of forest management based on integration of models with different perspectives have therefore attracted increasing interest in over the past decades. Results from these studies are surveyed in several of the chapters in the assessment reports from UN's Intergovernmental Panel for Climate Change. Nabuurs et al. (2007) sum up studies that integrate economic and ecological models to analyse the potential impacts of forest sequestration on the market for carbon allowances, and how increasing use of biofuels will affect energy markets. Easterling et al. (2007) survey results from studies that integrate ecological and economic models to assess impacts of climate change on forests, which demonstrate a notable impact on prices ( $p$ 289). However, they also point out problems connected to the integration of models. For example, models used to estimate the effects of climate change on forest production and composition do not match models used to predict forest yield. Sohngen et al. (2007) moreover point at the difficulties in matching economic and ecological models, which are developed with reference to widely different scales.

Economic models, similarly as ecological models are developed with different purposes and emphasise different properties. All models leave important aspects out, which in the end may affect the results to a certain degree. Hence, quantitative results from modelling exercises alone may be less important than the insights that the modelling provides in terms of explaining the results. Similarly, model properties are equally important as model results, especially on the background of the variety of properties of the different models that are being integrated. This paper discusses properties of integrated economic and ecological models used to analyse impacts of climate change on forests. It aims to give a background for selecting models to address given policy questions related to the management of forests impacted by climate change, and to help understand under what restrictions the results of integrated modelling apply.

To address challenges related to climate change, there are many reasons to take a global perspective and include all activities that may be affected by climate change. However, enlargening the scope of models usually implies more simplifications, and the analysis may be of little help if issues of major interest are hidden behind fixed relationships or resolved by simple assumptions. Then, it is usually better to give up the comprehensive, global scale and instead focus more on specific issues. One possibility is to leave out activities that are not directly affecting forests and the utilization of it. Another is to focus on smaller regions or areas.

Integrated models with a comprehensive, global perspective are basically economic models where impacts on forests are represented by a cost estimate. With the exception of the ISGM model (Reilly et al. 2007), global models with a rough representation of an ecological system are sector models. For more detailed descriptions of ecosystems, one has to turn to integrated, regional models. Studies by these models aim at showing how important economic drivers are for assessments of impacts of climate change. However, most of these include assumptions of fixed management strategies. To analyse alternative management strategies, more details are needed to the economic models than available at present. The availability of ecological models is not a limitation, however, as the ecological properties needed to analyse management options are well represented in several of them. In the last section of this paper, we discuss some potential for further integration of ecological and economic models to address forest management under climate change. 


\section{Forests and forestry in global integrated assessment models}

Climate change impacts on forests and implications for forest management can be addressed directly or indirectly in two classes of global integrated models. One class consists of macroeconomic models which integrates impacts of climate change. These models aim first and foremost to evaluate the timing of alternative climate policies with reference to the impacts of climate change, such as to answer how urgent are immediate emission reductions. The other class includes models that integrate sub models of selected systems, such as demography, the economy, the biosphere and the climate. The main application of these models is to produce consistent future pathways for the different systems, and analyse consequences of climate policy strategies for emissions and impacts of climate change.

\subsection{Global macroeconomic models with integration of climate change impacts}

The first well-known study of the economic impacts of climate change was made by Nordhaus (1991), who was interested to see when, and with how much, the world should reduce its emissions from a purely economic point of view. Nordhaus integrated the impacts of climate change in a model for economic growth, later known as the DICE model. The model deducts an estimate of total damages, expressed by the reduction of the gross domestic product (GDP), from the "base-line" GDP. The paper makes an assessment of whether the discounted cost of an abatement program would be covered by the discounted value of reductions in future damage, and runs several scenarios with more or less aggressive abatement program. Nordhaus concludes that only moderate abatement is beneficial in early periods. For the net present value of aggressive policies to be positive, the damages of climate change would have to be far beyond the expected.

Following this line of thought, other models have been developed to address the motivations for climate policy. In most of them, the impacts are represented by an aggregate of the total damage cost, which refers exclusively to the change in global mean temperature. The estimate for total damage is based separate assessments of damage at a given change in mean temperature, for example $2.5^{\circ} \mathrm{C}$. For other temperature changes, they apply a simple functional relationship between damage and global mean temperature. Most models assume increasing damage costs on the margin. Impacts to forests are usually included as a specified part of total damage costs for each region in the model.

The different models may refer to various studies of impacts of climate change on activities and phenomena, such as agriculture, forests, sea-level rise, extreme events etc. However, Fankhauser (1995) concluded, on the basis of early studies, that the estimates of the total damage at a given global mean temperature are relatively similar. When broken down to activities, the estimates diverge more substantially. For example, Nordhaus (1991) and later in Nordhaus and Boyer (2000) assume small impacts in forests for the US, at least up to an increase in global mean temperature of $+3^{\circ} \mathrm{C}$. An early study by Cline (1992) assumed, on the other hand, an annual loss of 3.3 billion US $\$$ at $+2.5^{\circ} \mathrm{C}$ in the US.

Later studies pay more attention to the benefits of adaptation and the $\mathrm{CO}_{2}$ fertilization effect of global warming on forests. For the world total, Tol (2002) assumes a significant productivity gain in boreal forests in his FUND model, also in the US, whereas tropical forests loose or are unaffected by climate change. The fertilization effect of $\mathrm{CO}_{2}$ was, however, dampened down after the findings of a reduced effect in free air experiments (Hendrey et al. 1999; Norby et al. 1999), but the main conclusion, that aggressive early cuts 
in emissions of greenhouse gases are hard to defend from an evaluation of costs and benefits, remained unaltered.

The Stern Review (Stern 2006) represents a different viewpoint, and claims that substantial emissions cuts are beneficial and urgent. The Stern Review applied the PAGE2002 model (Hope 2006) which uses the same damage cost approach as the models referred above, but assumes slightly higher impacts in accordance with later findings about impacts and the speed of climate change from the literature. The model defines impacts of climate change in broad categories, and does not specify impacts on forests. The explanation for the recommendation of aggressive climate policy lies mainly in their arguments in support of a low discount rate.

The global integrated macroeconomic models address the "big" question of to what extent emissions ought to be reduced to avoid climate change in the future from an economic viewpoint. The assessments must be considered very rough as all impacts are represented by a fixed cost (see e.g. Patt et al. 2009). Impacts to forests, for example, are independent on interlinkages between forests and demographic and economic development, other ecosystems, and climatic factors other than global mean temperature. Alternative management options are not considered by these models, although later studies include fixed estimates of the benefits of adaptation.

\subsection{Integration of model systems}

To address issues specific for certain sectors, such as the forestry sector, the characteristics of ongoing activities within sectors need a closer description. Some of the models in the second category of global integrated assessment models, where models of different systems are integrated, allow for a closer study of forest management and impacts of climate change on forestry. These models were originally developed to analyze greenhouse gas emissions, and to develop emission scenarios. Relatively few studies have been made so far by these models to address the impacts of climate change. The growing attention to the inherent complexities in utilizing the potential of forest management as a means to mitigate climate change has, however, initiated more focus on the interchange between the natural constraints and the various drivers behind the utilization of forests.

Four global integrated assessment models were used to develop representative concentrations pathways (RCP) as part of the preparatory phase for the development of new scenarios for the IPCCs Fifth Assessment Report. Three of them (AIM, IMAGE and MiniCAM) specify forests directly or include systems that, at least, allow for analyses of certain aspects of forest management, but do not address forest management in particular. The AIM model (Kainuma et al. 2006) combines a computable general equilibrium model, which specifies forestry as a separate sector, with bottom-up models for population, building, transport, water management and air. Being disconnected from ecosystems, only the impacts on forestry of economic market transactions can be addressed by the model, and forestry has not yet been focused in specific analyses. Management of forestry may, however, be discussed in the light of general equilibrium analysis in forestry and related sectors, such as to predict price signals to the sector resulting from given emission reduction strategies. The AIM model does not include impacts of climate change.

The IMAGE model (Bouwman et al. 2006) determines greenhouse gas emissions on the basis of economic and demographic drivers, by including partial equilibrium models for agriculture and energy, and derive implications for climate and air, biosphere, water and land-use. Emissions are determined by minimizing the costs of meeting equilibrium conditions in the energy markets. Integration of a simple biospheric model and a model for 
climate and air allows for analyses of impacts of climate change on forests. For example, van Vuuren et al. (2006) estimates an overall loss of vascular plant diversity between 7 and $24 \%$ in 2050 depending on the socioeconomic scenario. They conclude that land-use change is the main driver for the loss of species up to 2050, while climate change becomes an increasingly important factor behind the loss of species over the next century.

The MiniCAM model (Edmonds et al. 1997) integrates models for land-use, energy markets, and the atmosphere. Land-use is connected to agriculture, and the model incorporates demographics, natural resources and consumption in order to predict total emissions of greenhouse gases. The model is being used extensively to produce emissions scenarios and implications of global policies to control emissions. The model has also been connected to terrestrial models to study relationships between climate policy and ecosystems. Wise et al. (2009) show that the costs of emission control are being lowered when terrestrial systems are integrated in the model. Emissions control also turns out to have major impacts on agriculture. Over the next century, unmanaged ecosystems and forests are likely to expand, and the prices of food crops and livestock increase.

While the AIM model provides a general representation of the economy, but lacks a link to ecosystems, IMAGE and MiniCAM limits the economy to partial equilibrium models, but are more closely linked to ecosystems. The only model that integrates general equilibrium and ecosystems is the IGSM model (Prinn et al. 1999). Scenarios for greenhouse gases are thereby made consistent with socioeconomic scenarios. By means of a terrestrial biochemical model IGSM moreover allows for estimation of the response on vegetation of climate and atmospheric change, taking into account a broad range of impulses that affect the biosphere. This further strengthens the consistency between emission scenarios and assessment of the impacts on terrestrial systems. Using IGSM, Reilly et al. (2007) find that the effects of climate change and $\mathrm{CO}_{2}$ on crops, pasture and forests are, in general, positive over the current century. The effects of ozone are, however very detrimental, and the benefits of $\mathrm{CO}_{2}$ and climate may vanish unless ozone is strongly controlled.

Impacts on forests are recognized as a major part of the total impacts of climate change in global integrated models. So far, the models assume an overall positive impact of climate change up to a certain level of global temperature increase, at least in boreal forests. Whether the impacts on tropical forests will become positive or negative is more uncertain. However, studies by integrated economic and terrestrial models show that the change in global mean temperature alone vaguely indicates how climate change affects forests. The development of other ecosystems, drivers of land-use change and the future tropospheric ozone levels are essential, and suggest that forest management will play an important role for the final result. However, the potential for forest management is sparsely explored by integrated models with a global scale. The few studies that are available focus on widely different issues, which make it difficult to compare results and provide general conclusions about management. To get further insight one has to turn to regional and national studies.

\section{Impacts of climate change on forests and consequences for management}

Most of what is known about the socioeconomic implications of including forests in studies of climate change can, so far, be drawn from national studies of industrialized countries. The motivation in most of these studies is to explore the potential role forest management may play in climate change mitigation. Carbon may be sequestered in forests, and biomass 
refining and burning may be an attractive alternative to fossil fuels. As a consequence, both the mitigation potential and the energy markets will be affected if forest management is considered a part of mitigation policies.

There has been less attention to the impacts of climate change on forests, their economic consequences, and implications for forest management. The mitigation potential for forests may, however, be affected significantly by the impacts of climate change (Irland et al. 2001). This, coupled with a general increase in the awareness of adaptation strategies, explains why regional models of ecological systems and economic models are increasingly being integrated to address both impacts and forest management. As opposed to studies of the global scale, the regional and national studies are characterized more by modelling approaches than applications of a selection of specific models. In this section, we therefore discuss a number of studies that apply different approaches.

\subsection{Regional modelling studies of impacts on forests}

The earliest studies about possible economic implications of climate change on forests are found for the US. To assess the broader impacts of climate change on forests, Brinkley (1988) integrates an ecological model with a global trade model for forest products to see how ecological changes interact with resulting changes in the terms of trade for the US. The study uses a partial model for forestry and related economic sectors, and is further constrained by the assumption that the change the in growth of forests is determined fully by the change in mean temperature. More comprehensive models, which could take into account a broader set of drivers for forest growth, are usually available only for smaller regions within countries. The focus on sub-regions complicates integration with marketbased economic models, which are usually based on national accounts data without further geographical resolution.

To assess the national level impacts of climate change on forests, Callaway et al. (1994) links together projections of impacts from several regions in the US. They conduct a macroeconomic analysis by comparing equilibrium states (comparative statics) in order to analyse the responses of the ecological impacts to forests on market prices. Sohngen and Mendelsohn (1999) point out that adaptation to impacts of climate change on forests is subject dynamic processes, which are disregarded in comparative static approaches. Economic utilization ought to be related to the growth of the biomass rather than the stock. They argue that the implications for the choice of adaptation strategy may be large when price effects are substantial, as in the case of climate change impacts on forests. They link a dynamic model for forests to the aggregated dynamic economic model for the US and show that the timber market is likely to adapt considerably to climate change over time, thereby ameliorating the potential problems associated with ecological change.

The demand for timber is driven by the market for related manufacturing goods, and these markets are global. The importance of a comprehensive representation of global markets in analyses of the economic consequences of impacts of climate change in the forestry sector has been demonstrated in several studies of countries and regions. Sohngen and Sedjo (2005) analyze the impact on forest markets in the US of a global increase of timber supply. They conclude that consumers will probably gain, but producers may loose in terms of welfare. This loss indicates that a higher supply affects prices more than quantities because of limitations to substitution on the demand side. This result is confirmed by other studies in other developed regions of the world, and shows that the final socioeconomic impacts are strongly conditioned on market behaviour, which may be interpreted as adaptation. 
Solberg et al. (2003) use a regional model for timber markets to study the effects of an increase in supply of timber, with a resulting drop of timber prices in Europe. They show that the output in western parts of Europe will increase, while they forecast a reduction in the eastern parts. The overall positive welfare effect is derived from lower prices of forest products. Patriquin et al. (2003) study land-use changes in a general equilibrium model for Canada without focusing particularly on climate change. However, they include non-market services of the forests, which is of interest also in the context of climate change. They conclude that a decrease in forestry output following a reduction in forested land somewhat offsets the positive economic impacts generated by increased visitor activity.

Regional studies have to be based on exogenous assumptions about world market prices. Many global studies apply partial models, where the prices in sectors external to the model are assumed fixed. Hence, substitution between internal and external sectors is neglected. Lee and Lyon (2004) develop an integrated, partial model for the world timber market by linking the Hamburg global circulation model to an ecological model (BIOME3) and a timber supply model (TSM2000). The scenarios which include climate change lead to an increase in the world's forest supply when compared with a reference scenario without climate change. As in the regional scenarios, they conclude that timber prices decline also worldwide, while production increases, most substantially in the US and Russia.

In a similar study, Perez-Garcia et al. (2002) link a terrestrial ecosystem model with a global trade model for forest products. They find that climate change leads to increased growth, but that the resulting increase of production is significantly lower than the increase of growth, because of the drop in prices. This implies that low-cost forests contribute the main part of the increased supply. Tavoni et al. (2007) study the combined implications of climate change and sequestration policies, and its consequences for the energy market by linking an economic model with specification of the energy sectors, WITCH, to a forestry model. WITCH is a computable general equilibrium model where the intertemporal allocation of resources is modeled as a dynamic game (see Bosetti et al 2007). They show that linking forest management to the carbon market has the potential to alleviate the policy burden of offsetting about $50 \mathrm{ppmv}$ of $\mathrm{CO}_{2}$ concentrations, and significantly reduce the price of carbon.

Global and national studies are useful for pointing out how important management is for assessments of impacts in general. On a local scale, the variability of both ecological and economic conditions may result in widely different impacts within regions. Falkowski et al. (2000) point out that what appear as uncertainties in estimates of carbon sinks and climate change impacts in US forests are a result of variations rather than lack of knowledge. Variations are due to a broad range of natural processes and anthropogenic impulses, which are difficult to integrate in a comprehensive national model. Applying climate scenarios over the coming 100 years, Bachelet et al. (2004) uses a spatial model for the US and find that the eastern part of the country is becoming a carbon source over the next century, notably in Southeast, while the west is becoming a sink in the second half of the century.

Geographical variability represents a particular challenge for forest management, which, however, may be overcome. On the basis of several regional studies of developing countries Sathaye and Ravindranath (1998) conclude that if energy efficiency and forestry options are implemented consciously and carefully, emissions can be reduced at a negative cost without affecting economic growth in developing countries. Kadekodi and Ravindranath (1997) identify sequestration options in India depending on forest types, ownership patterns and land use patterns, and point out that the optimal strategy is a combination of management options, species choices and organizational arrangements. Also the impacts of 
climate change on forests, and further implications for the economy are likely to be subject to these factors, including forest management.

\subsection{Implications for the management of forests}

There are few modelling studies about how impacts of climate change may affect the management of forests available. A broad range of possible options that may apply as means to adapt to the impacts of climate change in forests have been proposed and discussed in the adaptation literature (see e.g. Spittelhouse and Stewart 2003). These studies provide a few quantifications of consequences or assessments of how managers are likely to respond to climate change impacts and price effects. Some lessons can, of course, be learned from studies of implications of external pressures, including pressures that may follow by climate change. Reed (1984) shows that the policy effect of forest fires risk is similar to that of an increase in the discount rate. In both cases, the optimal rotation period of the forest is affected. Higher risks moreover reduce the value of protecting forests. Haight et al. (1995) study the risks of damage on forests from hurricanes. They find that the relationship between the expected present value and rotation age is affected significantly by damage risks while the effects of salvage proportion and stand damage in the form of stem sweep are relatively small.

The apparent dependencies between external pressures and forest management call for a more explicit treatment of forest management in integrated studies of climate impacts on forests. This may further complicate integrated modelling, because most integrated models solve the system each period as if a static system (recursive dynamic), while forest management is a dynamic problem by nature: it is first and foremost from the growth we can take advantage. Sohngen and Mendelsohn (2003) therefore question the use of static models and comparative statics in integrated analyses of forest management and climate policy. They use a dynamic model to show that the cost of carbon sequestration may be lowered substantially by utilizing the dynamic properties described in their model, which allow agents to increase forested land over time and lengthen the rotation period.

In some later studies by the integrated models surveyed above, also the management of forests has been addressed. In their analysis by the MiniCAM-model, Wise et al. (2009) study the simultaneous effects on mitigation costs by integrating energy, climate and terrestrial systems. They show that coordinating the management of the different systems may lower mitigation costs, and trace profound implications for economic activities that are based on the utilization of natural resources. Unmanaged ecosystems and forests expand, while food crops and livestock prices rise. Reilly et al. (2007) study the combined effect of climate change, $\mathrm{CO}_{2}$ concentrations and ozone, and find that agriculture and forestry can adapt successfully to climatic changes if compared with the initial impacts on the natural environment. They emphasize, however, that the evaluation of the socioeconomic impacts of these changes will have to be considered with reference to the adequate measures of well-being rather than on the results for the sectors in question, thereby underlining the importance of using a comprehensive integrated tool for evaluations of impacts of climate change.

Integration of economic and ecological models applies to many issues of relevance for a determination of the impacts of climate change on forests and consequences of forest management. Integration of global models shows how economic impacts of climate change depend on ecosystems and how impacts to ecosystems depend on economic drivers. This provides some basic lessons about the challenges related to the achievement of sustainable development. To address management more specifically, one usually has to turn to national 
and regional modelling studies, where economic decisions are subject to assumptions about behaviour, usually competitive market behaviour. The descriptions of ecosystems can be made more specific in regional models, such as to distinguish between vegetation types. Most of the studies so far have focused on the effects of climate change impacts on prices in market equilibrium, which turn out to be substantial in all studies. There is a discussion whether static models can be used appropriately for these kinds of studies, or if models have to be dynamic. The distinction is important, but dynamic relationships may be represented adequately in static models under given assumptions, similar to how investments are represented in static economic models. Besides the traditional competitive markets, impacts of climate change have also been studied in game-theoretic settings, and with attention to non-economic impacts.

\section{Modelling impacts of climate change on forest ecosystems}

The models surveyed in the preceding section show how important management is for an assessment of impacts of climate change on forests. Common to the studies by economic models integrated with ecological models is that decisions are made according to some predefined behaviour, usually traditional utility maximising agents, who consider forests as a stock or property which may be transformed into an economic amount of wealth. There are no further evaluations of management options or choice among alternative management strategies.

Forest management serves, however, many purposes besides the economic and climatic issues, such as biodiversity and land-use, which have to be considered in addition to the economic and climatic concerns in practical policy. To be able to provide concrete recommendations for forest management under climate change, there is a demand for a broader perspective on management and inclusion of more details about the ecological systems. Economic models have not yet been applied to address alternative management options, but the potential of further integration between economic and ecological models for this purpose will be discussed in the next section. The abilities to extend the perspectives depend, however, on the availability of ecosystem models, and the information provided by these. To follow this up, we take a closer look at the ecosystem modelling in this section.

The models used to predict large-scale vegetation responses to future climate change can be categorized into deterministic and statistically based models. Statistically based models treat plant distributions as stochastic, and include spatial realizations of response surfaces, decision trees and bio-climatic envelopes. Statistical functions are used to generate expected distribution of species, which depend on the combined effects of a range of environmental variables. A brief description of a selection of models under each of the categories is given in the following sections, and the required inputs and outputs from each model are provided in Table 1.

\subsection{Statistically-based models}

There are large uncertainties about how climate change impacts the growth of forests. The uncertainties are related both to the magnitude and character of climate change, and to the various responses to a changing climate in forests (Dixon and Wisniewski 1995). Uncertainties in the input variables and parameters of forest growth models can be addressed by the use of Monte Carlo-techniques (van der Voet and Mohren 1994). For example Woodbury et al. (1998) apply a modeling approach to analyze the potential effects 

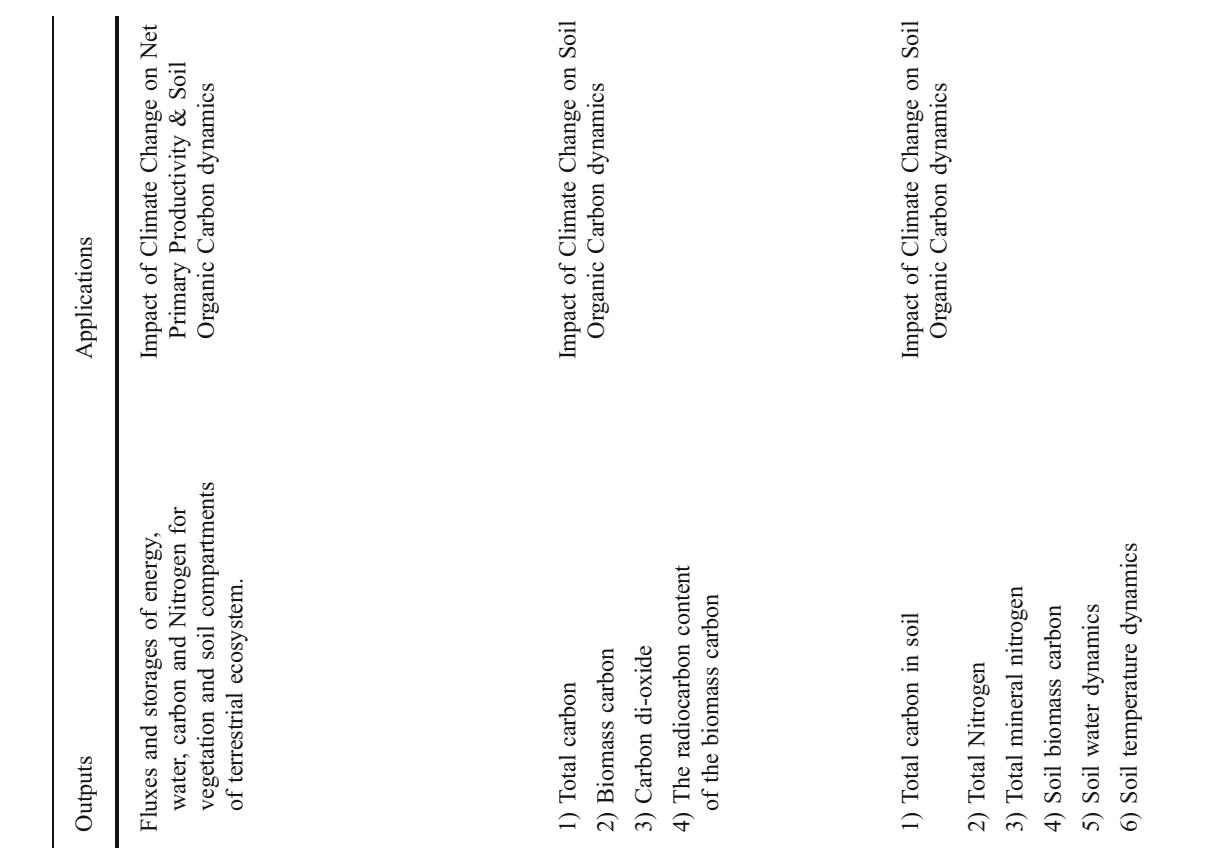

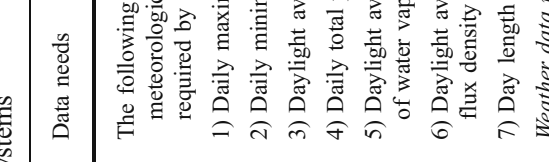

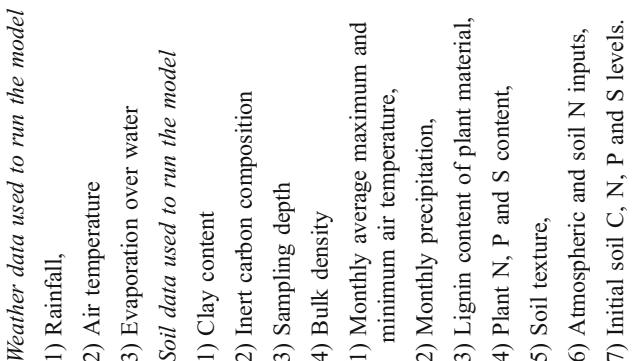
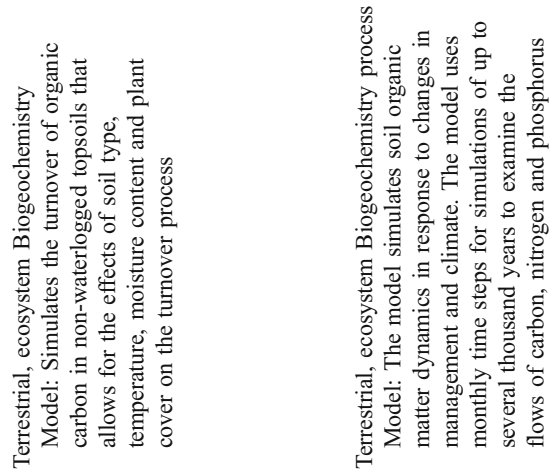

帘 

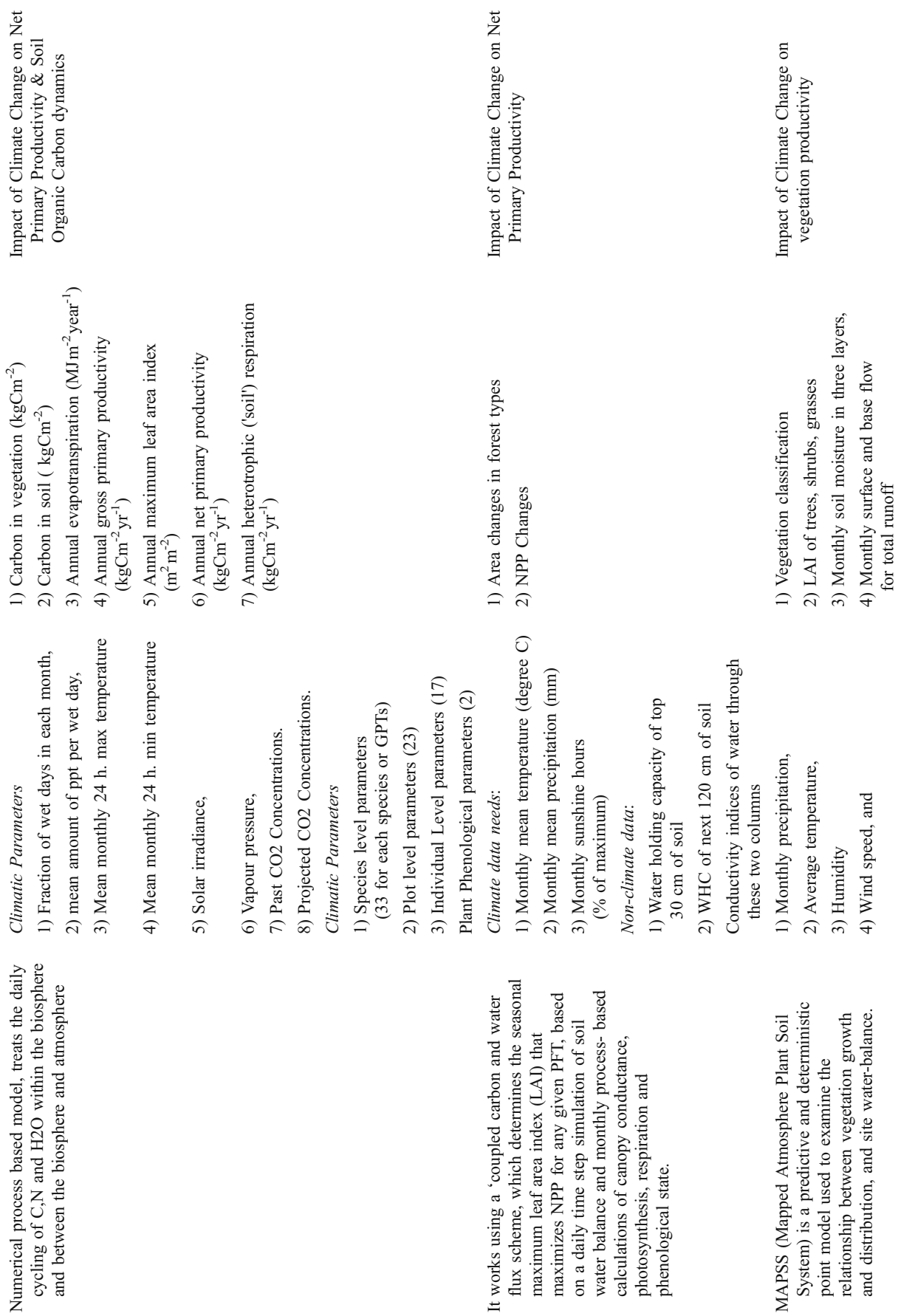

魚 


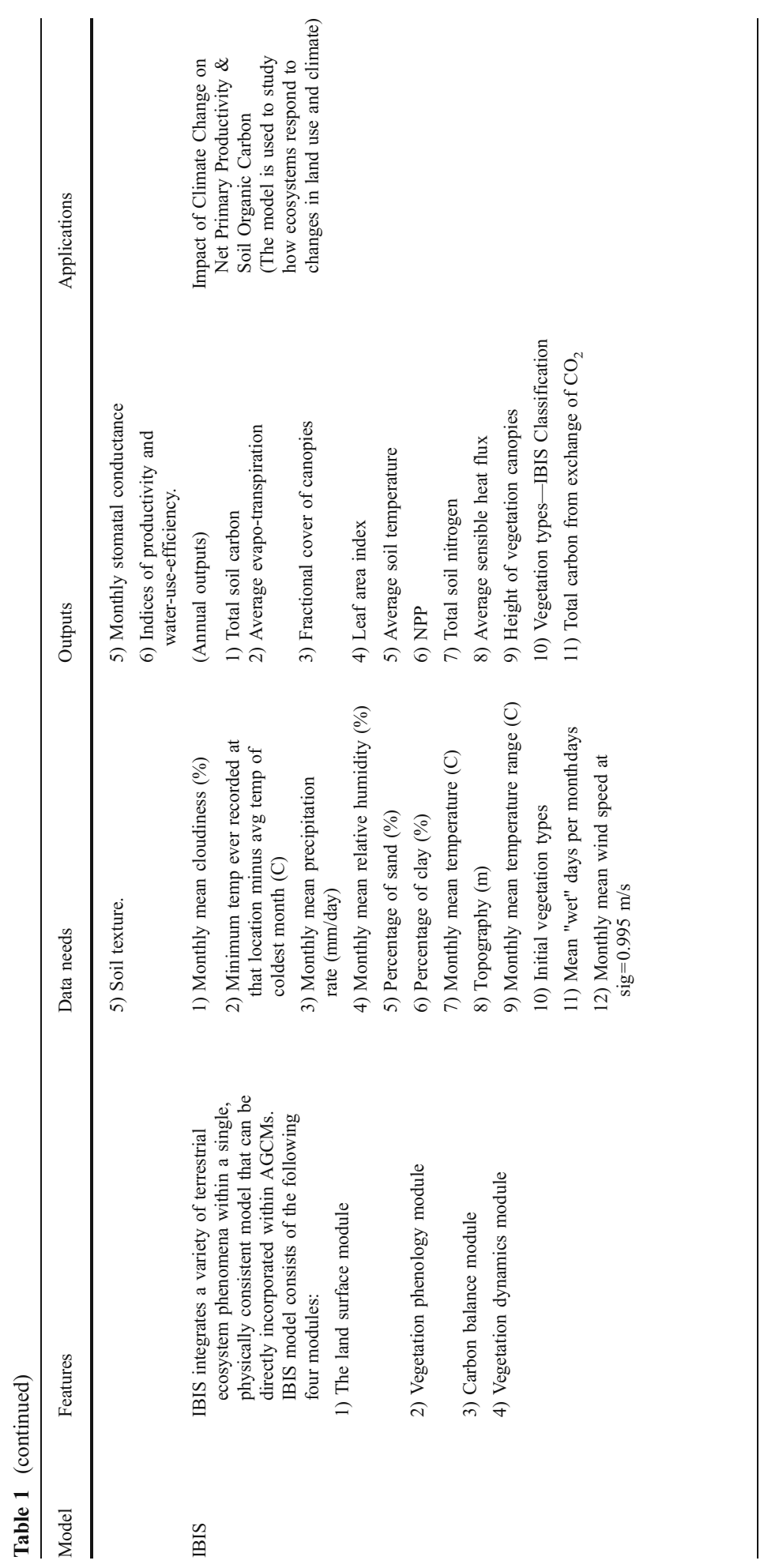


of climate change on the growth of loblolly pine using available research and regional monitoring data. Model inputs and functional relationships within the model are defined by statistical distributions. Then, Monte Carlo-techniques were used to estimate frequency distributions for the model output.

Another statistical model, DISTRIB, was used to project total forests and the distribution of eighty tree species in various community types in the eastern United States. A predictive vegetation mapping (Prasad and Iverson 2000) was used in a regression tree analysis (RTA) to model the spatial distribution of tree importance values for the 80 tree species using 33 climatic, edaphic and land-use variables. With this model, they predict how distributions of trees may change if the equilibrium level of $\mathrm{CO}_{2}$-concentrations is doubled compared with the preindustrial level, as estimated by several global circulation models (GCM).

\subsection{Deterministic models}

The term "forest dynamics" spans huge ranges both in time and space: The enzymatic reactions of photosynthesis operate within fractions of a second; foliage development takes a few weeks, while tree growth lasts decades to centuries, and the dynamics of soil organic matter span millennia (Bugmann 1994). On the other hand, the germination of a seed takes place on a few square centimeters, a sun fleck moving over the forest floor covers a few square meters; a dominant tree in the canopy occupies 0.01-0.1 ha, and the quasiequilibrium of a forest landscape may be reached on the scale of several hectares (Shugart and Urban 1989). Accordingly the deterministic forest models are classified with respect to a variety of criteria. Broadly they can be seen as the models which follow temporal scale or those which follow spatial scales.

\subsubsection{Temporal scale models}

Temporal scale models can be distinguished by the modeling of the vegetation response to a changing climate. The static models determine shifts of equilbria while the dynamic models determine the process of change resulting from a perturbation of the initial state.

Static biogeographical models assume equilibrium conditions in both climate and terrestrial vegetation in order to predict the distribution of potential vegetation by relating the geographic distribution of climatic parameters to the vegetation. The equilibrium approach applies only to large scales in nature as it ignores dynamic processes. In general, it requires much less information than dynamic models, and provides estimates of potential magnitude of the vegetation response at regional to global scales. These equilibrium models are restricted to the estimation of the steady-state conditions. Prominent examples of static models include BIOME (Kaplan et al. 2003), and MAPPS.

The dynamic biogeographical models capture the transient response of vegetation or simple biomes to a changing environment using explicit representation of key ecological processes such as establishment, tree growth, competition, death, nutrient cycling (Shugart and West 1980; Shugart 1984; Botkin 1993). Dynamic models also require much more information on the characteristics of species than is easily available or even known for some areas of the globe (Solomon 1986). These models are used in predictions at the regional scale or for ecosystems, but have not yet been applied at the global scale (Smith et al. 1994; Shugart and Smith 1996). Prominent examples of dynamic models include IBIS (Foley et al. 1996), Hybrid (Friend et al. 1997), LPJ (Sitch 2000), and Triffid (Cox et al. 1998). 


\subsubsection{Spatial scale models}

The spatial scale models can be divided into regional and global models. At the regional level, ecosystems are analyzed at a sub-process level, which are difficult to capture and manage at the global level. Within these spatial models, there are generally two classes of global vegetation models, biogeography models and biogeochemistry models. The biogeography models place emphasis on determination of what can live where, but either do not calculate or only partially calculate the cycling of carbon and nutrients within ecosystems. The biogeochemistry (Gap) models simulate the carbon and nutrient cycles within ecosystems, but lack the ability to determine what kind of vegetation could live at a given location.

Biogeochemistry models project changes in basic ecosystem processes such as the cycling of carbon, nutrients, and water. These models are designed to predict changes in nutrient cycling and primary productivity. They are also known as "gap models" and simulate all the dynamic relationships for small representative areas. They simulate the cycles of carbon, nutrients and water in terrestrial ecosystems. The inputs to these models are temperature, precipitation, solar radiation, soil texture, and atmospheric $\mathrm{CO}_{2}$ concentration. The plant and soil processes simulated are photosynthesis, decomposition, soil nitrogen transformations mediated by microorganisms, evaporation and transpiration. Common outputs from biogeochemistry models are estimates of net primary productivity, net nitrogen mineralization, evapotranspiration fluxes and the storage of carbon and nitrogen in vegetation and soil. Some of the popular models include BIOME-BGC (Running and Hunt 1993), CENTURY (Parton et al. 1993), and the Terrestrial Ecosystem Model (TEM, McGuire et al. 1992).

Biogeography models simulate shifts in the geographical distribution of major plant species and communities i.e. they analyze the essential environmental conditions over entire continents to estimate the type of vegetation that is most likely to cover a given area. These types of models are best suited for assessing broad-scale changes in vegetation. They project the local dominance of various terrestrial vegetation forms. The models determine the broad distribution of major categories of woody plants, and include response limitations with reference to ecophysiological constraints. Specific aspects of community composition are determined, such as the competitive balance of trees and grasses.

The biogeography models predict the dominance of different plant species under different climatic and environmental scenarios. The several biogeography models used for such assessment include the Mapped Atmosphere Plant Soil System (MAPSS; Neilson 1995), BIOME3 (Haxeltine and Prentice 1996), and MC1 (Bachelet and others 2001). Input datasets for biogeography models mainly include latitude, mean monthly temperature, windspeed, solar radiation, and soil properties such as texture and depth. All of these models project vegetation responses to changes in the concentrations of $\mathrm{CO}_{2}$, but through different mechanisms.

To sum up, there is a broad scope of deterministic ecological models to use in integrated studies of forest management under climate change. What type of model to use depends on the issue at stake, and each type has its advantages and shortcomings. What is important is that the strengths of the models that are being integrated are supported by each other. As forest management is often a question of controlling the growth of biomass, dynamic models may be a natural choice, but they require much more information than static models, information that may not be available on the global scale. The spatial dimension may also be decisive for the ability to include impacts of changes in nutrient cycling, but biochemistry models apply mainly on specific species in specific areas. To predict changes 
for larger areas, one has to turn to biogeography models and focus on the dominance of different plants.

\section{Challenges to integration of ecological and economic models}

Integrated models applied until now has contributed to the understanding of how forests may be impacted by climate change, although they have their limitations when compared with outcome of more specialized, non-integrated models. In general, the integrated models provide an opportunity to produce more realistic predictions of perturbations in both economic and ecological systems, but coupling of models developed on the basis of different academic traditions may be disturbing when it comes to the interpretation of results. Ecological models can be understood as generalizations of physical processes, where human interference is considered a perturbation to the system. Economic models, on the other hand, aim at predicting the consequences of decision maker's responses to perturbations in their environment. What is important to take into account when generalizing physical processes may differ from what decision makers consider important to their actions. It is, therefore, not always clear how results from integrated ecological and economic models should be interpreted: Are they meant primarily as numerical predictions of the future, or do they aim at providing insights to the social consequences of decision processes?

For integrated studies of forests, forestry, climate change and climate policy, the different regards to the choice of model assumptions in ecological and economic models become apparent in the choice of scales on which models operate. A main contribution from the economic model is to show how heavily decisions are influenced by world markets. Hence, it is vital to properly represent the main drivers of world markets prices. In order to do so, market decisions will have to be highly simplified to allow for interpretations of drivers for the model output. These generalizations are not necessarily applicable to studies on lower levels, where institutional constraints, specific natural conditions and social patterns may play a prominent role.

Ecological models are generalizations of physical processes of species. These processes are known from studies on a very detailed level, such as field studies. The different ecological models emphasize different properties of the physical processes, such as dynamic processes, stochastic evolution or equilibrium states, but they assume that management is exogenous. This gives rise to a mismatch when economic models and ecological models are integrated: the physical processes on which economic decisions are based do not appear from the ecological model, and the real economic drivers of ecological change cannot be read from the economic model.

Sohngen et al. (2007) observe this by pointing at the different scales on which economists and ecologists traditionally work. They claim that economists and ecologists have not worked seriously together to better match the models. This indicates that there are potential gains in further capturing the strengths of ecological models to improve the insights of economic decision-making in forests, and to better utilize the insights from economic models to improve the description of anthropogenic interference in ecological models.

The potential for gaining further insights into the interlinkages between forest management and impacts of climate change on forests is illustrated by some studies of mitigation. The GCOMAP model (Sathaye et al. 2006) is designed to assess mitigation potentials in forest systems, and includes three modules. The first computes annual changes 
in carbon stock on the basis of biophysical characteristics such as biomass yield, carbon content of biomass and soil, etc. Both the accumulation of carbon and its release from decay of vegetation and products are recorded separately on land planted each year. The second module computes the financial viability of management options on the basis of estimates of costs and benefits. The third module estimates changes in land-use under selected scenarios for carbon prices.

Ravindranath et al. (2010) uses the BIOME4 model to provide input to the first module of GCOMAP and study mitigation potentials under different global emission scenarios. They also modify the GCOMAP model to include the dynamic carbon uptake rates provided by BIOME4. They find that the increase in total mitigation potential estimated by BIOME4 accumulates to nearly $1 \mathrm{GtC}$, or $21 \%$, over the next 100 years under the IPCC A2-scenario (Nakicenovic and Swart 2000). The economic potential is, however, less. When integrated with GCOMAP, the potential falls to $6 \%$. For the more moderate B2scenario, the initial mitigation potential falls by $646 \mathrm{MtC}$, or $14 \%$, whereas the economic potential is reduced to $5 \%$. Hence, the relative share of the economic potential increases as the total potential is reduced.

A similar effect of including management objectives in ecological models is found in Khatun et al. (2010), who address the effect of varying carbon prices on land availability for afforestation and reforestation projects in the State of Karnataka in India. They couple output from the Lund-Potsdam-Jena global dynamic vegetation model with GCOMAP to assess the effectiveness of using large scale forestry project under the Clean Development Mechanism in three IPCC emissions scenarios. It turns out that none of the forestry projects are viable at current carbon prices. The authors propose that price projections for carbon are provided separately to pinpoint how sensitive clean development mechanisms are to the market for carbon permits. Separate price projections are also useful with respect to the different user perspectives of forest management, which includes governments, forestry officials, private entities and rural communities.

When turning to adaptation, better integrated models could advance the analysis of resiliency associated with climate change, both from an ecological and a socioeconomic viewpoint. The examples above indicate that economic decisions and management have a large impact on the extent to which ecological changes are being affected by human intervention. Sohngen et al. (2007) point out, in particular, the need to better represent the role of economics in ecological systems, for example by assessing how adaptation affects the ecological impacts of climate change.

\section{Conclusions}

Forests represent a huge potential for mitigation, while at the same time being affected significantly by climate change itself (Ravindranath 2007). This explains why integrated studies of climate policy and forest management have been subject to a large amount of studies, which cover a broad range of issues. So far, most of these studies are somehow related to the mitigation of climate change. Studies of impacts and adaptation are less frequent. There is, however, a growing interest for approaching mitigation as an aspect of forest management, which includes adaptation to climate change. A study by Ravindranath (2007) highlights the need to assess and promote mitigation-adaptation synergies in the forest sector.

The models used for studies of economic impacts of climate change where forests and forestry are integrated fall into two categories: one is founded on general macroeconomic 
models, including general equilibrium models, which also describes activities within forestry. The other category is regional and partial models, which allows for closer studies of forest management.

Forests and forestry are poorly represented in most of the general models, although to various degrees. Impacts on forests are often considered part of an aggregated impact of climate change, or forests may be considered a part of a stock of natural resources. Some models include forests indirectly by a land-use module. There are only a few examples of further linking land-use module to ecological models, which enable a more direct consideration of forest issues. The studies that have been carried out indicate, however, a large potential of addressing new and important issues.

Regional and partial models allow for more direct integration of ecological models, as it allows for a better match between the scales on which the models traditionally operate. However, only relatively few studies have addressed impacts and adaptation options until now. Available studies point at the importance of separating the initial effect of climate change on ecosystems and the economic question of utilizing this potential. Generally, the economic impacts of forest responses to climate change are moderated significantly when compared with the initial ecological effect because of market responses. For example, the benefits of an increase in forest productivity seem to be gained in terms of lower market prices, hence benefiting users rather than produces.

Some recent studies indicate the advantages of further integration of ecologic and economic models, pointing out potentially significant benefits of multipurpose management regimes. On the other hand, an ecological response also needs to be represented more comprehensively, for example in order to address combined ecological effects of management on ozone- and $\mathrm{CO}_{2}$-concentrations.

The complexity of both economic systems and ecological systems suggest that integration of models will have to be chosen on the background of the purpose of the analysis. Most economic and ecological models can be classified with respect to similar criteria, such as scale, temporal and inter-temporal and deterministic and stochastic. But some differences, such as the spatial dimension, remain challenging. Regional, national and global economic models are fed by data delineated by institutional criteria, such as country borders, and cannot easily be broken down to the spatial resolution of the ecological models. Issues related to forest management and impacts of climate change are rarely studied, however, and it is possible to point out a range of problems which deserve more attention, and which may be analyzed by means of small and simple adjustments of existing tools.

Acknowledgements Thanks to three anonymous referees for helpful comments to an earlier version. Research for this publication was conducted under the project "Impact of climate change on tropical forest ecosystems and biodiversity in India", funded by the Royal Norwegian Embassy, as a collaboration between Indian Institute of Science in Bangalore and CICERO in Oslo. We thank the Royal Norwegian Embassy for their support.

Open Access This article is distributed under the terms of the Creative Commons Attribution Noncommercial License which permits any noncommercial use, distribution, and reproduction in any medium, provided the original author(s) and source are credited.

\section{References}

Bachelet D, Lenihan JM, Daly C, Neilson C, Ronald P, Ojima DS, Parton WJ (2001) MC1: a dynamic vegetation model for estimating the distribution of vegetation and associated carbon, nutrients, and water technical documentation. Version 1.0. Gen 
Bachelet D, Neilson RP, Lenihan JM, Drapek RJ (2004) Regional differences in the carbon source-sink potential of natural vegetation in the U.S.A. Environ Manage 33(Supplement 1):S23-S43

Bosetti V, Massetti E, Tavoni M (2007) The WITCH model. Structure, baseline, solution. Nota di Lavoro 10.2007. Fondazione Eni Enrico Mattei, Milano

Botkin DB (1993) Forest dynamics: an ecological model. Oxford University Press, Oxford

Bouwman AF, Kram T, Klein K, Goldewijk, ed. (2006) Integrated modelling of global environmental change. An overview of IMAGE 2.4, Netherlands Enviornmental Assessment Agency, MNP publ. no. 500110002/2006. Bilthoven

Brinkley CS (1988) A case study of the effects of $\mathrm{CO}_{2}$-induced climatic warming on forest growth and the forest sector: B. Economic effects on the world's forest sector. In: Parry ML, Carter TR, Konjin NT NT (eds) The impacts of climatic variations on agriculture. Kluwer, Dortrecht

Bugmann H (1994) On the ecology of mountainous forests in a changing climate: a simulation study, Ph.D. Thesis No. 10'638. Swiss Federal Institute of Technology Zurich (ETHZ), Switzerland, p 258

Callaway M, Smith J, Keefe S (1994) The economic effect of climate change for US forests. Final Report, US EPA, Washington

Cline WR (1992) The economics of global warming. Institute of International Economics, Washington

Cox PM, Huntingford C, Harding RJ (1998) A canopy conductance and photosynthesis model for use in a GCM land surface scheme. J Hydrol 212-213:79-94

Dixon RK, Wisniewski J (1995) Global forest systems: an uncertain response to atmospheric pollutants and global climate change? Water Air Soil Pollut 85(1):101-110

Easterling WE, Aggarwal PK, Batima P, Brander KM, Erda L, Howden SM, Kirilenko A, Morton J, Soussana J-F, Schmidhuber J, Tubiello FN (2007) Food, fibre and forest products. In: Parry ML, Canziani OF, Palutikof J-P, van der Linden PJ, Hanson CE (eds) Climate change 2007. Impacts, adaptation and vulnerability. Contribution of Working Group II to the Fourth Assessment Report of the Intergovernmental Panel of Climate Change, Cambridge University Press, Cambridge, UK, pp 273-313

Edmonds J, Wise M, Pitcher H, Richels R, Wigley T, MacCracken C (1997) An integrated assessment of climate change and the accelerated introduction of advanced energy technologies. Mitig Adapt Strateg Glob Change 1:311-339

Falkowski P, Scholes RJ, Boyle E, Candall J, Canfield D, Elser J, Grupbler N, Hibbard K, Hogberg P, Linder S, Mackenzie FT, Moore B III, Pedersen T, Rosenthal Y, Seitzinger S, Smetacek V, Steffen W (2000) The global carbon cycle: a test of our knowledge of earth as a system. Science 290:291-296

Fankhauser S (1995) Valuing climate change. The economics of the greenhouse, CSERGE - Earthscan Publ Ltd, London

Foley JA, Prentice IC, Ramankutty N, Levis S, Pollard D, Sitch S, Haxeltine A (1996) An integrated biosphere model of land surface processes, terrestrial carbon balance, and vegetation dynamics. Glob Biogeochem Cycles 10(4):603-628

Friend AD, Stevens AK, Knox RG, Cannell MGR (1997) A process-based, biogeochemical, terrestrial biosphere model of ecosystem dynamics (Hybrid v3.0). Ecol Modell 95:249-287

Haight RG, Smith WD, Thomas J (1995) Hurricanes and the economics of Loblolly pine plantations. For Sci 41(4):675-688

Haxeltine A, Prentice IC (1996) BIOME3 An equilibrium terrestrial biosphere model based on ecophysiological constraints, resource availability and competition among plant functional types. Glob Biogeochem Cycles 10(4):693-710

Hendrey GR, Ellsworth DS, Lewin KF, Nagy J (1999) A free-air enrichment system for exposing tall forest vegetation to elevated atmospheric $\mathrm{CO}_{2}$. Glob Change Biol 5:293-309

Hope $\mathrm{C}$ (2006) The marginal impact of $\mathrm{CO}_{2}$ from PAGE2002: an integrated assessment model incorporating the IPCC's five resons for concern. Integr Assess J 6(1):19-56

Irland LC, Adams D, Alig R, Betz BJ, Chen C-C, Hutchins M, McCarl BA, Skog K, Sohngen BL (2001) Assessing socioeconomic impacts of climate change on US forests, wood product markets, and forest recreation. Bioscience 51(9):753-764

Kadekodi GK, Ravindranath NH (1997) Macro-economic analysis of forestry options on carbon sequestration in India. Ecol Econ 23(3):201-223

Kainuma M, Masui T, Fujino J, Hanaoka T, Ashina S, Harasawa H, Hijioka Y, Takahashi K, Hanasaki N, Matsuoka Y, Fujiwara T, Kawase R, Akashi O, Shimada K, Hibino G, Miyashita M, Ehara T, Shukla PR (2006) Asia-Pacific integrated model (AIM). Scenarios modeling and policy analysis. National Institute for Environmental Studies. Tsukuba

Kaplan JO, et al. (2003) Climate change and Arctic ecosystems: modeling, paleodata-model comparisons, and future projections. Journal of Geophysical Research-Atmosphere, 108 No. 8171

Khatun, K., Valdes P, Knorr W, Rajiv K, Chaturvedi R, Ravindranath NH (2010) The mitigation potential through using afforestation and reforestation in a changing climate: a case study for Karnataka (in press). 
Lee DM, Lyon KS (2004) A dynamic analysis of the global timber market under global warming: an integrated modeling approach. South Econ J 70(3):467-489

McGuire AD, Melillo JM, Joyce LA, Kicklighter DW, Grace AL, Moore B III, Vorosmarty CJ (1992) Interactions between carbon and nitrogen dynamics in estimating net primary productivity for potential vegetation in North America. Glob Biogeochem Cycles 6:101-124

Nabuurs GJ, Masera O, Andrasko K, Benitez-Ponze P, Boer R, Dutschke M, Elsiddig E, Ford-Robertson J, Frumhoff P, Karjalainen T, Krankina O, Kurtz WA, Matsumoto M, Oyhantcabal W, Ravindranath NH, Sanz Sanchez MJ, Zhang X (2007) Forestry. In: Metz B, Davidson OR, Bosch PR, Dave R, Meyer LA (eds) Mitigation. Contribution from Working Group III to the Fourth Assessment Report of the intergovernmental panel of climate change. Cambridge University Press, Cambrige

Nakicenovic N, Swart R (eds) (2000) Emissions scenarios. Special report from the Intergovernmental Panel of Climate Change, Cambridge University Press, Cambridge

Neilson RP (1995) A model for predicting continental-scale vegetation distribution and water balance. Ecol Appl 5:362-385

Norby RJ, Wullenschelger SD, Gunderson CA, Johnson DW, Ceulemans R (1999) Tree responses to rising $\mathrm{CO}_{2}$ in field experiments: implications for future forests. Plant Cell Environ 22:683-714

Nordhaus WD (1991) To slow or not to slow: the economics of the greenhouse effect. Econ J 101:920-237

Nordhaus WD, Boyer J (2000) Warming the world. Economic models of global warming. MIT, Cambridge

Parton WJ, Scurlock JMO, Ojima DS, Gilmanov TG, Scholes RJ, Schimel DS, Kirchner T, Menaut J-C, Seastedt T, Moya EG, Kamnalrut A, Kinyamario JL (1993) Observations and modeling of biomass and soil organic matter dynamics for the grassland biome worldwide. Glob Biogeochem Cycles 7:785-809

Patriquin NJ, Alavalapati JRR, Wellstead AM, Young SM, Adamowicz WL, White WA (2003) Estimating impacts of resource management policies in the foothills model forest. Can J For Res 33(1):147-155

Patt A, van Vuuren D, Berkhout K, Aaheim A, Hof A, Isaac M, Mechler R (2009) Adaptation in integrated assessment modeling: where do we stand? Climatic Change (forthc.)

Perez-Garcia J, Joyce LA, McGuire AD, Xiao X (2002) Impacts of climate change on the global forest sector. Clim Change 54:439-461

Prasad AM, Iverson LR (2000) A climate change atlas for 80 forest tree species of the eastern United States. U.S. Department of Agriculture, Forest Service, Northeastern Research Station, Delaware

Prinn R, Jacoby H, Sokolov A, Wang C, Xiao X, Yang Z, Eckhaus R, Stone P, Ellerman D, Melillo J, Fitzmaurice J, Kicklighter D, Holian G, Liu Y (1999) Integrated global system model for climate policy assessment: feedbacks and sensitivity systems. Clim Change 41:469-546

Ravindranath NH (2007) Mitigation and adaptation synergies in the forest sector. Mitig Adapt Strateg Glob Change 12:843-853

Ravindranath NH, Chaturvedi RK, Joshi NV, Sukumar R, Sathaye J (2010) Implications of climate change on mitigation potential estimates for forest sector in India. Mitig Adapt Strateg Glob Change. doi:10.1007/s11027-010-9256-8

Reed WJ (1984) The effects of the risk of fire on the optimal rotation of a forest. J Environ Econ Manage 11:180-190

Reilly J, Paltsev S, Fetzer B, Wang X, Kicklighter D, Melillo J, Prinn R, Sarofim M, Sokolov A, Wang C (2007) Global economic effects of change in crops, pasture, and forests due to changing climate, carbon dioxide, and ozone. Energy Policy 35:5370-5383

Running SW, Hunt ER Jr (1993) Generalization of a forest ecosystem process model for other biomes, BIOME-BGC, and an application for global-scale models. In: Ehleringer JR, Field C (eds) Scaling processes between leaf and landscape levels. Academic, San Diego, pp 141-158

Sathaye JA, Ravindranath NH (1998) Climate change mitigation in the energy and foresty sectors of developing countries. Annu Rev Energy Env 23:387-437

Sathaye JA, Makundi W, Dale L, Chan P, Andrasko K (2006) GHG mitigation potential, costs and benefits in global forests: a dynamic partial equilibrium approach. The Energy Journal-Special Issue-Multigas Greenhouse Gas Mitigation. LBNL-55743

Shugart HH (1984) A theory of forest dynamics: the ecological implication of forest succession models. Springer-Verlag, New York

Shugart HH, West DC (1980) Forest succession models. Bioscience 30:308-313

Shugart HH, Smith TM (1996) A review of forest patch models and their application to global change research. Clim Change 34:131-153

Shugart HH, Urban DL (1989) Factors affecting the relative abundances of tree species. In: Grubb PJ, Whittaker JB (eds) Toward a more exact ecology. 30th Symposium of the British Ecological Society, Blackwell, Oxford a.o. 249-273

Sitch S (2000) The role of vegetation dynamics in the control of atmospheric CO2 content, $\mathrm{PhD}$ thesis, Lund University 
Smith TM, Leemans R, Shugart HH, eds (1994) The application of patch models of vegetation dynamics to global change issues. GCTE Workshop Summary, Kluwer Academic Publishers, NTLD

Sohngen BL, Mendelsohn R (1999) The impacts of climate change on the US timber market. In: Mendelsohn R, Neumann JE (eds) The impact of climate change on the United States Economy. Cambridge University Press, Cambridge

Sohngen BL, Mendelsohn R (2003) An optimal control model of forest carbon sequestration. Am J Agric Econ 85(2):448-457

Sohngen BL, Sedjo R (2005) Impacts of climate change on forest product markets: implications for north american producers. Forest Chron 81(5):669-674

Sohngen B, Alig R, Solberg B (2007) The forest sector, climate change, and the global carbon cycleenvironmental and economic implications, mimeo, http//:aede.osu.edu/people/shongen.1/forests/ccforests.htm

Solberg B, Moiseyev A, Kallio AM (2003) Economic impacts of accelerating forest growth in Europe. Fore Policy Econ 5(2):157-171

Solomon AM (1986) Transient response of forests to CO2 induced climate change: Simulation modeling experiments in eastern North America. Oecologia 68:567-579

Spittelhouse DL, Stewart RB (2003) Adaptation to climate change in forest management. BC J Ecosyst Manage 4(1):1-11

Stern NH (2006) The stern review. The economics of climate change, Cambridge University Press

Tavoni M, Sohngen B, Bosetti V (2007) Forestry and the carbon market response to stabilize climate. Energy Policy 35:5346-5353

Tol RSJ (2002) Estimates of the damage costs of climate change. Part 1: benchmark estimates. Environ Resour Econ 21(1):47-73

van der Voet H, Mohren GMJ (1994) An uncertainty analysis of the process-based growth model FORGRO. For Ecol Manage 69:157-166

van Vuuren DP, Sala OE, Pereia HM (2006) The future of vascular plant diversity under four global scenarios. Ecology and Society 11 2:25 (online)

Wise M, Calvin K, Thomson A, Clarke L, Bond-Lamberty B, Sands R, Smith SJ, Janetos A, Edmonds J (2009) Implications of limting $\mathrm{CO}_{2}$ concnetrations for land use and energy. Science 324:1183-1186

Woodbury PB, Smith JE, Weinstein DA, Laurence JA (1998) Assessing potential climate change effects on loblolly pine growth: a probabilistic regional modeling approach. For Ecol Manage 107:99-116 